\title{
Identification of NCAM that interacts with the PHE-CoV spike protein
}

Wei Gao ${ }^{1,3 \dagger}$, Wenqi He ${ }^{1 \dagger}$, Kui Zhao ${ }^{1}$, Huijun Lu², Wenzhi Ren³ ${ }^{3}$ Chongtao Du', Keyan Chen', Yungang Lan', Deguang Song ${ }^{1 *}$, Feng Gao ${ }^{1 *}$

\begin{abstract}
Background: The spike proteins of coronaviruses associate with cellular molecules to mediate infection of their target cells. The characterization of cellular proteins required for virus infection is essential for understanding viral life cycles and may provide cellular targets for antiviral therapies.

Results: We identified Neural Cell Adhesion Molecule (NCAM) as a novel interacting partner of the PHE-CoV S protein. A T7 phage display CDNA library from N2a cells was constructed, and the library was screened with the soluble PHE-CoV S glycoproteins. We used a coimmunoprecipitation assay to show that only the NCAM was a binding partner of spike protein. We found that a soluble form of anti-NCAM antibody blocked association of the PHE-CoV with N2a cells. Furthermore, double-stranded siRNA targeted against NCAM inhibited PHE-CoV infection.
\end{abstract}

Conclusions: A novel interaction was identified between NCAM and spike protein and this association is critical during PHE-COV infection.

\section{Background}

Porcine hemagglutinating encephalomyelitis coronavirus (PHE-CoV) is a member of the Coronaviridae family, which causes porcine encephalomyelitis [1]. The mechanisms by which PHE-CoV infects cells and causes disease are not well characterized, nor are the factors known which determine the host and tissue specificity. The cellular receptor which is a crucial determinant of the tropism of several viruses, is not known in the case of PHE-CoV.

The spike glycoprotein of coronavirus is a major determinant of neurovirulence [2-5]. The coronavirus spike glycoprotein is responsible for viral attachment to the cellular receptor and fusion of the viral and cellular membranes, resulting in virus entry [4]. Several types of receptors for coronavirus have been previously identified [6]. The murine carcinoembryonic antigen cell adhesion molecule 1 (CEACAM1) and related murine glycoproteins in the carcinoembryonic antigen family of the Ig

\footnotetext{
*Correspondence: Songdg6301@126.com; gaofeng2010852010@yahoo.cn

+ Contributed equally

${ }^{1}$ College of Animal Science and Veterinary Medicine, Jilin University,

Changchun 130062, PR China

Full list of author information is available at the end of the article
}

superfamily are the receptors for the murine coronavirus mouse hepatitis virus [4]. The aminopeptidase N (APN) glycoproteins are the receptors for human coronavirus 229E (HCoV-229E), the transmissible gastroenteritis virus of swine, and the feline coronavirus of genetic group 1 [7-10].

PHE-CoV has a strong tropism for the central nervous system (CNS) [11]. The virus spreads via peripheral nerves to the CNS. PHE-CoV propagates mainly in the CNS, and nerve cells are a main target for virus replication [12]. The molecular mechanisms and specific proteins involved in adhesion of PHE-CoV to host cells have not yet been elucidated.

In this work, we discovered that the PHE-CoV S protein interacted with NCAM by screening a T7 phage cDNA library from Neuro-2a (N2a) cells. It is necessary to investigate these interactions with host-cell proteins, as discovering these interactions may be helpful in the identification of host proteins participating in important stages of the virus life cycle, such as virus entry, virion morphogenesis, and virion release. In addition, established protein contacts could serve as targets for antiviral chemotherapy. 


\section{Methods \\ Animals}

Specific pathogen-free lines of piglets were purchased from the Centre for Medicine Animal Research (Jilin, China). Animal procurement and transportation into the HEPA-ventilated caging systems and performance of the experimental-challenge tests were performed in accordance with the guidelines for animal experimentation of Jilin University.

\section{Viruses and cell culture}

The $67 \mathrm{~N}$ strain of PHE-CoV [13] was propagated and assayed by the plaque method in N2a cell culture, as described previously [14], and the titres were expressed as plaque-forming units (PFU). The cell lines were obtained from the American Type Culture Collection (ATCC), N2a (ATCC CCL-131) and 293T (ATCC CRL11268). These cells were maintained in Dulbecco's modified Eagle's medium (Invitrogen, Carlsbad, CA) supplemented with $10 \%$ cosmic calf serum (HyClone, Logan, UT) and $2 \mathrm{mM} \mathrm{L-glutamine.} \mathrm{All} \mathrm{of} \mathrm{the} \mathrm{cell}$ cultures were maintained at $37^{\circ} \mathrm{C}$ in $5 \% \mathrm{CO}_{2}$.

\section{Protein production}

The recombinant S protein of PHE-CoV was obtained using a Pichia pastoris yeast expression system. The S gene was subcloned by PCR. The forward primer for the S gene (5'-CGGAATTCGTGCCATCTATTAGCTCTGAAGT-3') and the reverse primer for the $S$ gene (5'TTGCGGCCGCAAGTATGCCCTGGCCTGTAATG-3') introduced EcoRI and NotI sites, respectively. Following gel purification, using the QIAquick gel extraction kit (Qiagen, Valencia, CA), the purified PCR products were ligated into the EcoRI and NotI sites of the pPICZ $\alpha A$ vector (Invitrogen, San Diego, CA), yielding pPICZ $\alpha$ AS. GS115 yeast cells, transformed with pPICZaAS (Invitrogen, San Diego, CA), were grown at $30^{\circ} \mathrm{C}$ in $100 \mathrm{ml}$ liquid Buffered Methanol Complex Medium (BMMY) (Invitrogen, San Diego, CA) with $0.1 \mathrm{mg} / \mathrm{ml}$ Zeocine (Invitrogen, San Diego, CA). Production of the His6tagged fusion $\mathrm{S}$ protein was induced with $1 \%$ methanol. After $5 \mathrm{~d}$, the protein was collected from the supernatant. The His6-tagged recombinant $S$ protein was purified by nickel affinity chromatography with the HisTrap HP column (Amersham Biosciences AB, Uppsala, Sweden).

\section{Preparation of the T7 phage display library from N2a cells}

Total RNA from the N2a cells was extracted using standard methodology, while mRNA was purified using the poly (A) Quick mRNA Isolation Kit (Promega, Southampton, UK). A cDNA library was constructed with 10 $\mu \mathrm{g}$ mRNA, following the manufacturer's instructions for the OrientExpress Random Primer cDNA Synthesis kit (Novagen, Madison, WI), with some modifications. The first and second strand cDNA syntheses are simple reactions that are carried out sequentially in the presence of 5-methyl dCTP, which protects any internal EcoR I and Hind III restriction sites from digestion. The cDNA was treated with T4 DNA polymerase to blunt the ends, and EcoR I/Hind III Directional Linker was added at the end. Following, the cDNA fragments were digested with EcoRI and HindIII. The Mini Column Fractionation Kit (Novagen, Madison, WI) is used for rapid and effective size fractionation of DNA and removal of small molecules $(<300 \mathrm{bp})$ from DNA solutions by gel filtration. The cDNA fragments were ligated to the arms of T7 Select 10-3b and packaged in vitro using a T7 packaging extract (Novagen, Madison, WI), according to the manufacturer's directions. The packaged phage were amplified in liquid media with the host Escherichia coli BLT5403.

\section{Panning}

In order to screen the clones that display the adhesion protein, the cDNA library from N2a cells was panned with the $\mathrm{S}$ protein. The 96 -well plates were coated with $200 \mu \mathrm{l}$ of the purified S protein $(2 \mathrm{mg} / \mathrm{ml})$ in coating buffer $(50 \mathrm{mM} \mathrm{NaHCO} 3 \mathrm{pH} 9.6)$ overnight at $4{ }^{\circ} \mathrm{C}$. Nonspecific sites were blocked with $5 \%$ bovine serum albumin for $1 \mathrm{~h}$ at $37^{\circ} \mathrm{C}$, and a $100 \mu \mathrm{l}$ aliquot of the $\mathrm{T} 7$ phage display library (containing $6.4 \times 10^{10} \mathrm{PFU} / \mathrm{ml}$ ) was added to the wells and incubated for $2 \mathrm{~h}$ at $37^{\circ} \mathrm{C}$. Following this, the wells were washed five times with PBST (phosphate-buffered saline containing $0.1 \%[\mathrm{v} / \mathrm{v}]$ Tween-20) to discard any unbound phages. The bound phages were eluted with $200 \mu \mathrm{l}$ of T7 elution buffer (TBS in 1\% sodium dodecyl sulfate [SDS]) and amplified by infecting Escherichia coli BLT5403 [15]. The amplified phages were then subjected to another four rounds of panning as described above, to enrich the clones that were highly specific for the S protein of PHE-CoV.

\section{Sequence analysis}

After five rounds of panning, the final enriched specific clones were plated and single pure plaques were isolated. The cDNA inserts in these plaques were amplified by PCR using primers (T7 Select Up primer: 5'GGAGCTGTCGTATTCCAGTC-3'; T7 Select Down primer: 5'-AACCCCTCAAGACCCGTTTA-3') flanking the inserts. Each PCR consisted of 30 cycles of denaturation at $94^{\circ} \mathrm{C}$ for $1 \mathrm{~min}$, annealing at $50^{\circ} \mathrm{C}$ for $1 \mathrm{~min}$, and extension at $72^{\circ} \mathrm{C}$ for $1 \mathrm{~min}$. The reaction also included an initial denaturation step at $94^{\circ} \mathrm{C}$ for $5 \mathrm{~min}$ and a final extension step at $72^{\circ} \mathrm{C}$ for $7 \mathrm{~min}$. After PCR 
amplification, the products were purified by Qiaquick columns (Qiagen, Hilden, Germany) and were then sequenced.

The nucleotide sequence of the protein that was most predominantly recognized by the $\mathrm{S}$ protein of PHE-CoV was a hypothetical gene of N2a cells http://www.ncbi. nlm.nih.gov/blast.

\section{Transfections and co-immunoprecipitation}

The PHE-CoV $67 \mathrm{~N}$ strain did not infect the 293T cell line. To investigate the interactions between the PHECoV $67 \mathrm{~N}$ strain and the chimeric protein, 293T cells were transfected with the pcDNA3.1 (+) (Invitrogen, Carlsbad, CA) expression plasmid containing the chimeric gene, using Lipofectamine 2000 (Invitrogen, Carlsbad, CA). The transfections were performed following the manufacturers' protocols $[16,17]$. After $24 \mathrm{~h}$, the cells were replated in selective media containing 50-100 $\mu \mathrm{g} / \mathrm{ml}$ ampicillin [18], and single ampicillin-resistant clones were selected.

For co-immunoprecipitation, cells were lysed in $500 \mu \mathrm{l}$ of radioimmune precipitation buffer $(150 \mathrm{~mm} \mathrm{NaCl}, 5$ $\mathrm{mg} / \mathrm{ml}$ sodium deoxycholate, $50 \mathrm{~mm}$ Tris- $\mathrm{HCl}, \mathrm{pH} 7.5$, $1 \%$ Nonidet P-40, $0.1 \%$ SDS) supplemented with freshly added protease inhibitors. After rotating for $1 \mathrm{~h}$ at $4^{\circ} \mathrm{C}$, cell lysates were cleared by centrifugation at $8000 \times \mathrm{g}$ for $10 \mathrm{~min}$ at $4^{\circ} \mathrm{C}$. The $100-\mathrm{ml}$ aliquot of lysate was incubated with $3 \mathrm{ml}$ of glutathione-Sepharose beads conjugated with His6-tagged fusion $\mathrm{S}(6 \mathrm{mg})$. Cell lysates were electrophoresed through $12 \%$ sodium dodecyl sulfate-polyacrylamide gels and transferred to polyvinylidene difluoride membranes. The blots were blocked at room temperature for $3 \mathrm{~h}$ with 3\% BSA in PBS containing Tween $20(0.05 \%)$ and then incubated overnight with a 1:2,000 dilution of the rabbit anti-S protein antibody. The blot were washed again and exposed to films [19].

\section{Flow Cytometry}

We investigated whether a soluble form of the rabbit anti-NCAM antibody (Santa Cruz, California, USA, CATALOG: SC-10735) could inhibit PHE-CoV binding to N2a cells. The anti-NCAM antibody was diluted and added to N2a cells. The cells were incubated with 100 $\mu \mathrm{l}$ of soluble anti-NCAM antibody $(10-25 \mu \mathrm{g} / \mathrm{ml})$ for $1 \mathrm{~h}$ at $37^{\circ} \mathrm{C}$. The controls included cells with goat IgG (1:1000) (Maixin, Fuzhou, China). Following this, the wells were washed five times with PBS (phosphate-buffered saline). After 2 hours, the PHE-CoV $67 \mathrm{~N}$ strain (diluted to yield 20 to 40 plaques/well in $20 \mu \mathrm{l}$ ) was added to N2a cells that had been grown at a plating density of $10^{5}$ cells per well in 24-well plates. After a 48-h infection, PHE-CoV binding was detected with the Rabbit PHE-CoV antiserum. The N2a cells were coated with $20 \mu \mathrm{l}$ of rabbit anti-PHE-CoV antiserum at 1:1,000 per well for $1 \mathrm{~h}$ at $37^{\circ} \mathrm{C}$. The cells were washed three times in PBS (pH7.4). Fluorescein (FITC)-conjugated goat anti-rabbit IgG $(\mathrm{H}+\mathrm{L})$ (Jackson ImmunoResearch Laboratory, West Grove, PA) was added to the N2a cell mixtures for $30 \mathrm{~min}$. After 48 hours, the samples were analyzed on a BD FACSAria flow cytometer [6].

\section{Transfection of siRNAs and PHE-CoV infection}

Double-stranded siRNA were designed based on the NCAM gene sequence to various regions of the genome using the Ambion siRNA Design tool http://www. ambion.com. Sequences were designed using (NN) N19 nt (where $\mathrm{N}$ is any nucleotide) and a GC content of less than $50 \%$. The siRNAs targeted against the NCAM gene were synthesized at Sangon Biotech Co, Ltd. RNAs were deprotected and annealed using the Silencer siRNA Construction Kit (Ambions,Austin,USA). Doublestranded siRNA transfect into N2a cells using RNAimax (Invitrogen, Carlsbad,CA) as the transfection reagent. Before transfection, the cells were washed and resuspended in $900 \mu \mathrm{l}$ of RPMI 1640 medium. Cationic lipid complexes, prepared by incubating $2 \mu \mathrm{M}$ siRNA duplexes with $3 \mu \mathrm{l}$ of oligofectamine in $100 \mu \mathrm{l}$ of RPMI 1640 medium, were added to the wells. The effect of gene silencing was examined by indirect immunofluorescence. The resulting N2a cells were named N2a KD cells.

After a $24 \mathrm{~h}$ transfection, the PHE-CoV $67 \mathrm{~N}$ strain was added to N2a KD cells. As control, the virus was added to mock-transfected siRNA N2a cells. At the indicated timings, culture supernatants were collected for plaque assay.

\section{Results}

\section{Display of the CDNA library from N2a cells on T7 phage}

T7 phage was enumerated using the plaque assay method on LB semi-solid medium. Based on the PFU after in vitro packaging, the T7 phage display library from the N2a cells was calculated to contain $1.5 \times 10^{7}$ independent clones. The amplified library with a titer of $6.4 \times 10^{10} \mathrm{pfu} / \mathrm{mL}$ was used for the subsequent screening. Amplification of the inserts in randomly selected clones revealed that the library contained $>90 \%$ recombinants, with an average insert size of $>300 \mathrm{bp}$. Because the size of the phage display library exceeded the estimated number, most of the expressed genes were represented in this library (Fig. 1).

\section{Affinity selection and sequence analysis of specific genes recognized by the $S$ protein}

The entire screening process was repeated for five rounds. After each round of panning, there was an increase in the number of clones, suggesting that the 


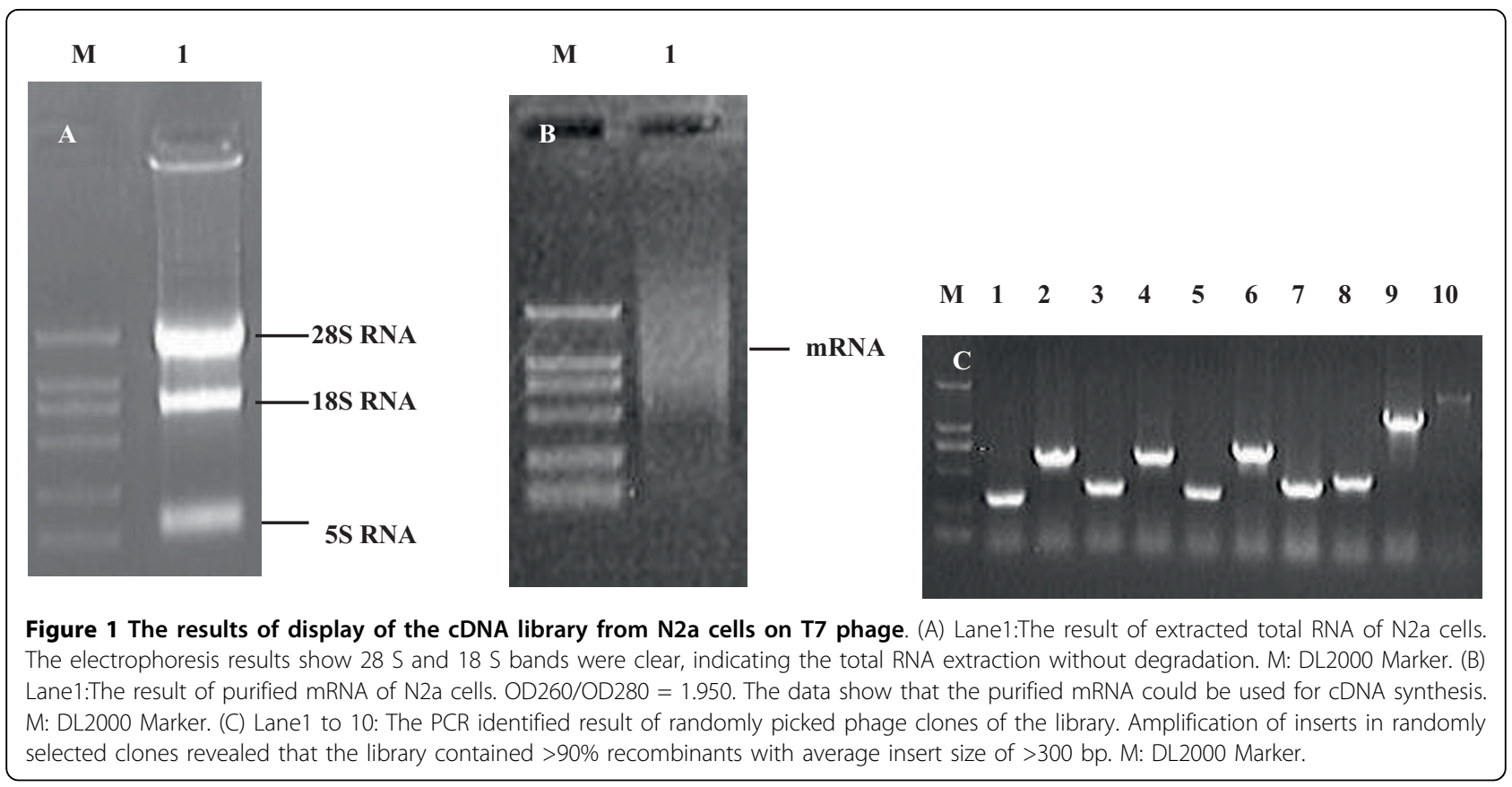

procedure enriched for specific clones (Table 1). By the end of the fifth round of panning, there was a 320-fold increase in specific clones compared to the number of clones that were obtained after the first round. However, there was no further enrichment after additional rounds of panning.

Approximately 100 clones were randomly picked from individual plaques, and the DNA sequences of clones were amplified by PCR and analyzed on an agarose gel to determine the insert size. Approximately $38 \%$ of the phage clones had an insert size of $830 \mathrm{bp}, 25 \%$ had an insert size of $750 \mathrm{bp}, 22 \%$ had an insert size of $400 \mathrm{bp}$ and $15 \%$ had an insert size of 250 bp (Fig. 2). The clones were then further sequenced.

DNA sequences of the inserts from the fifth round of panning were determined and compared using BLAST analysis. Panning yielded four clones (Table 2), as follows: neural cell adhesion molecule (NCAM), splicing factor $3 \mathrm{~b}$, subunit 2 (Sf3b2), histone deacetylase 2 (Hdac2), and ribosomal protein S13 (RPS13).

Table 1 Phage enrichment results after different rounds of panning

\begin{tabular}{cccc}
\hline $\begin{array}{c}\text { Round of } \\
\text { panning }\end{array}$ & $\begin{array}{c}\text { Phage applied } \\
\text { (PFU/ml) }\end{array}$ & $\begin{array}{c}\text { Phage eluted } \\
\text { (PFU/ml) }\end{array}$ & $\begin{array}{c}\text { Enrichment } \\
\text { (fold) }\end{array}$ \\
\hline 1 & $1.6 \times 10^{10}$ & $5.5 \times 10^{5}$ & $3.4 \times 10^{-5}$ \\
2 & $2.8 \times 10^{10}$ & $5.3 \times 10^{6}$ & $1.9 \times 10^{-4}$ \\
3 & $2.5 \times 10^{10}$ & $8.3 \times 10^{6}$ & $3.3 \times 10^{-4}$ \\
4 & $3.4 \times 10^{10}$ & $5.1 \times 10^{7}$ & $1.5 \times 10^{-3}$ \\
5 & $3.8 \times 10^{10}$ & $6.5 \times 10^{7}$ & $1.7 \times 10^{-3}$ \\
\hline
\end{tabular}

\section{Expression of NCAMSf3b2, Hdac2 and RPS13}

The full lengths cDNA of these genes (NCAM: GenBank no. NM_001081445Sf3b2: NM_030109, Hdac2: NM_008229 and RPS13: NM_026533) was used to construct the transfect plasmid. These four protein expression levels were detected by a BioPhotometer Plus (Eppendorf, Hamburg, Germany). The correct expression of NCAM, Sf3b2, Hdac2 and RPS13 in 293T cells was studied by immunoblotting. The four proteins antibodies were purchased from Santa Cruz biotechnology, inc (NCAM antibody CATALOG: SC-10735; Sf3b2 antibody: SC-101133; Hdac2 antibody: SC-7899; RPS13 antibody: SC-162098). The polypeptides migrated to a molecular weight corresponding to NCAM (140 kDa), Sf3b2 (100 kDa), Hdac2 (55 kDa) and RPS13 (17 kDa), respectively (Fig. 3).

\section{Identification of NCAM as a binding partner of the S protein}

To identify the binding partner of S protein, co-immunoprecipitation was performed. The 293T cell lysates were immunoprecipitated with anti-S protein antibody. Supernatants of 293T cells transfected with plasmid encoding the screened gene were immunoprecipitated with S protein and anti-S protein antibody. The 293T cells transfected with vector alone were controls. When the soluble form of NCAM was incubated with S protein, a $160 \mathrm{kDa}$ band was observed (Fig. 4). However, Sf3b2, Hdac2 and RPS13 were not immunoprecipitated with S protein. Moreover, the PHE-CoV spreads via peripheral nerves to the central nervous system. Sf3b2, 


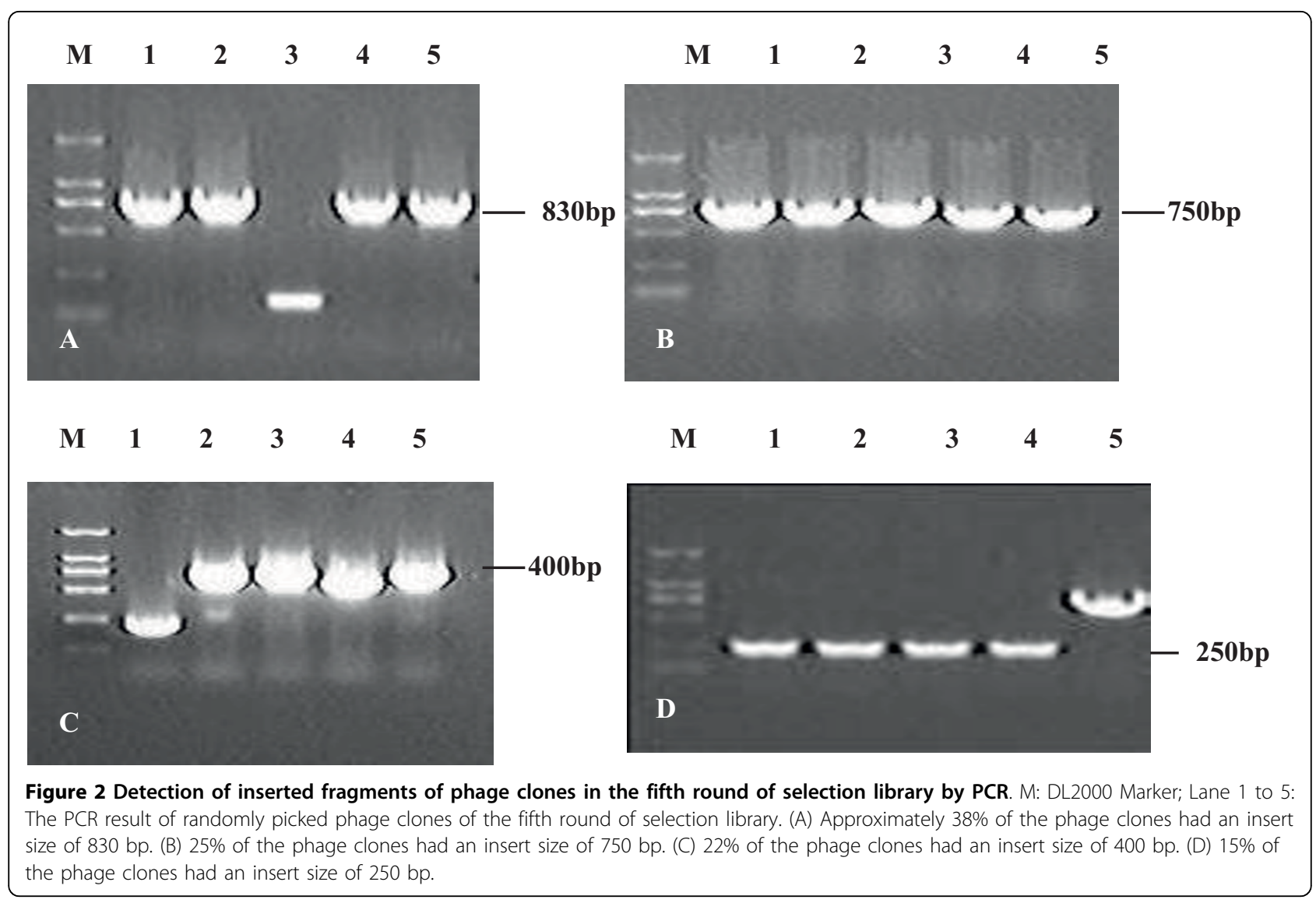

Hdac2 and RPS13 are all expressed in various tissues and cells. Therefore, we did not analyze them further. The data demonstrate a specific, high-affinity association between the $\mathrm{S}$ protein of PHE-CoV and NCAM.

\section{Anti-NCAM antibody inhibit binding of PHE-CoV to N2a cells}

We investigated whether anti-NCAM antibody could block the association of PHE-CoV with N2a cells. Virus binding was detected using PHE-CoV antiserum and FITC-conjugated goat anti-rabbit IgG $(\mathrm{H}+\mathrm{L})$. FACS analysis showed that the binding rate of PHE-CoV to N2a cells with control goat IgG was 99\%. However, the 10 $\mu \mathrm{g} / \mathrm{ml}$ anti-NCAM antibody inhibited PHE-CoV binding to N2a cells by $75 \%$. With the increased anti-NCAM antibody concentration in the cell blocking, it was

Table 2 BLAST analysis identification of fifth round-insert sequences

\begin{tabular}{ccc}
\hline Clone name & GenBank no. & Identity \\
\hline NC-1 & NM_001081445 & neural cell adhesion molecule (NCAM) \\
NC-2 & NM_030109 & splicing factor 3b, subunit 2 (Sf3b2) \\
NC-3 & NM_008229 & histone deacetylase 2 (Hdac2) \\
NC-4 & NM_026533 & ribosomal protein S13 (RPS13) \\
\hline
\end{tabular}

noticed that, the inhibition rate reached about 95\% (Fig. 5). However, the proliferation of virus could not be suppressed completely. The result was that a soluble form of the anti-NCAM antibody blocked the association of PHE-CoV with the N2a cells.

\section{The NCAM siRNAs inhibit PHE-CoV infection for prolonged periods of time}

All oligonucleotide sequences used to produce NCAM siRNA are shown in Table 3 . Three siRNAs were designed based on the NCAM sequence (Accession no. NC_000075). The effect of NCAM gene silencing in N2a cells was confirmed by flow cytometry. The NCAM protein expression was completely suppressed within 72 h (Fig. 6). To determine the antiviral effects of siRNAs, N2a cells were transfected with NCAM siRNAs and challenged with the PHE-CoV $67 \mathrm{~N}$ strain 24 hours later. The effects of the siRNAs in N2a cells stained after transfection and infection with PHE-CoV was analysed by indirect immunofluorescence (Fig. 7). After further culture for 5 days, the reduction of cell-free viral particle production was assessed by plaque assay. Plaque assay analysis of the cultures after infection revealed a corresponding reduction in siRNA-transfected N2a cells. The NCAM siRNAs inhibited PHE-CoV infection compared 


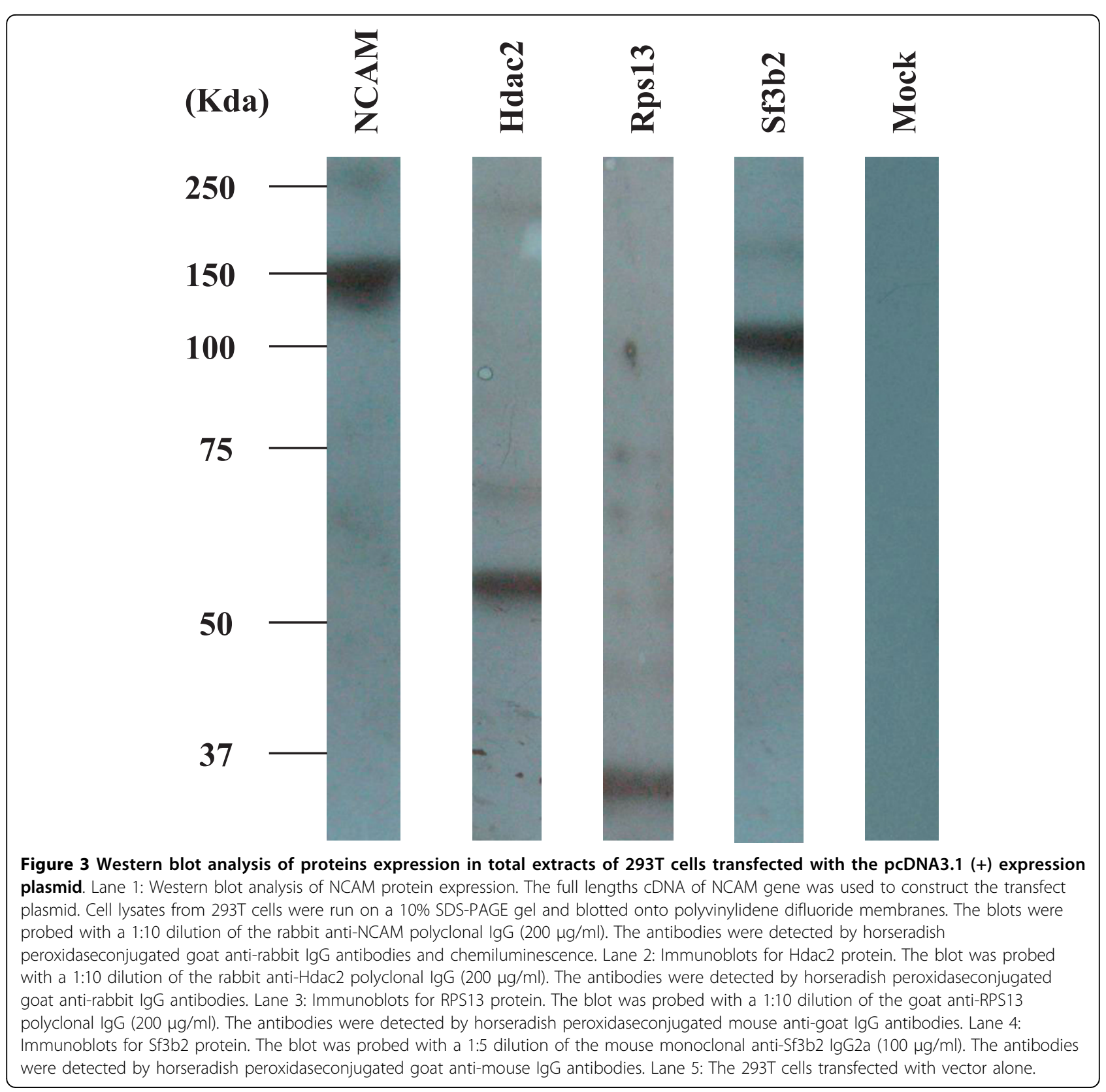

to controls throughout the 84-hour period of observation (Fig. 8). These results demonstrated that expression levels of NCAM correlate with PHE-CoV infection. NCAM might participate in the attachment and invasion of N2a cells.

\section{Discussion}

In this report, we describe the discovery of a novel interaction between NCAM and spike protein of PHECoV. To our knowledge, this is the first study that used a phage display-based cDNA expression library for screening and affinity panning with the PHE-CoV spike protein to identify the interaction between PHE-CoV and N2a cells. Co-immunoprecipitation analysis showed that the NCAM was a binding partner of spike protein. In addition, FACS analysis demonstrated that a soluble form of the anti-NCAM antibody blocked association of PHE-CoV with N2a cells. Moreover, double-stranded siRNA targeted against NCAM inhibit PHE-CoV infection. The results suggest that NCAM might participate in virus infection.

Neural Cell Adhesion Molecule (NCAM, also the cluster of differentiation CD56) is a homophilic and heterophilic binding glycoprotein expressed on the surface of 


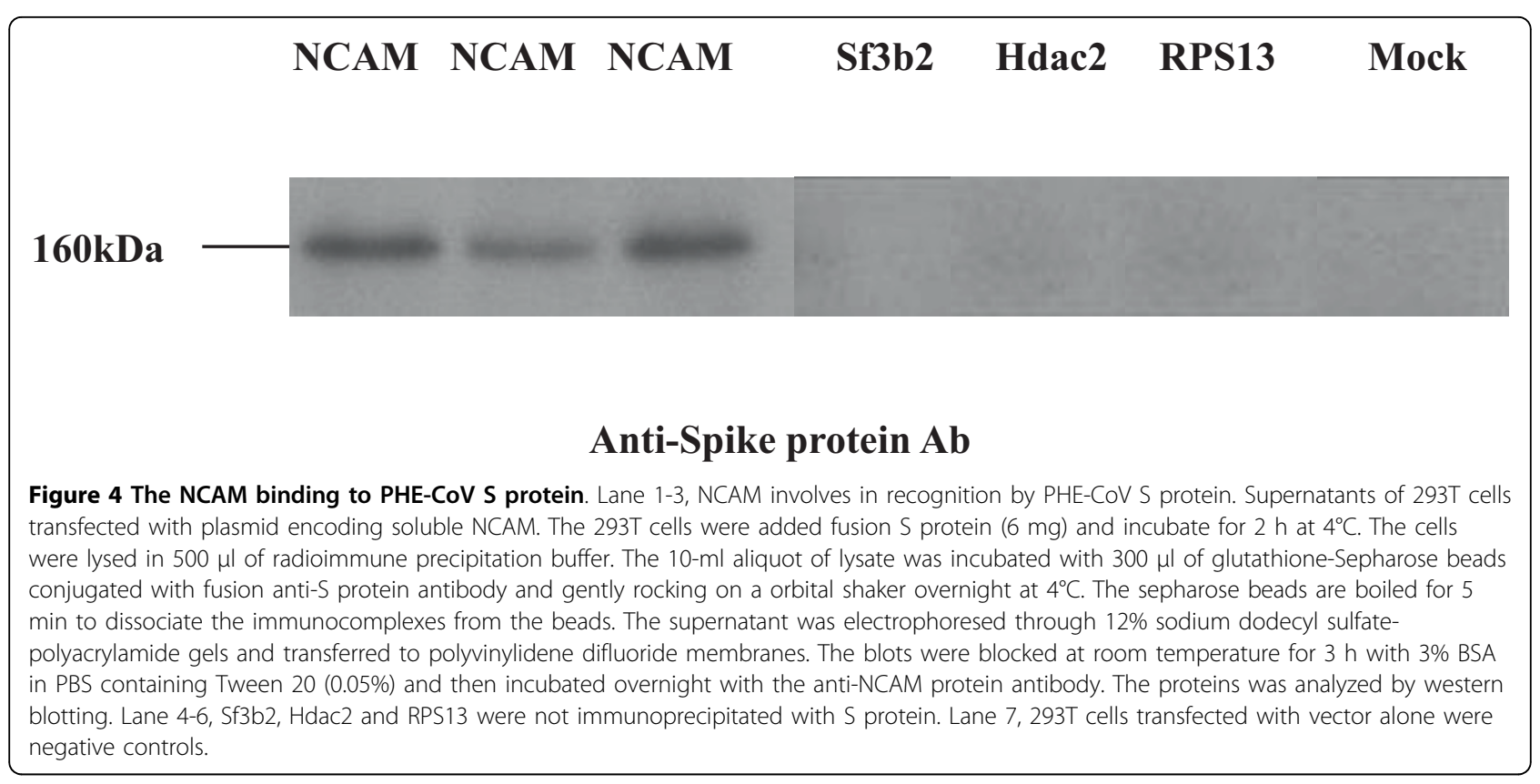

neurons, glia, skeletal muscle and natural killer cells [20]. NCAM is a member of the immunoglobulin supergene family of Cell adhesion molecules (CAMs) [21]. CAMs play important roles in cell-cell and cell-extracellular matrix interactions in both mature and developing nervous system [22]. During development, they are involved in cell migration, axon guidance, target recognition, and synapse formation; while in the mature nervous system, they maintain synaptic connections, cellcell contacts, and neuron-glial interactions [22]. Injuries to the nervous systems break the stable state of the tissues and the repair of damaged tissues and regeneration of axons require the participation of CAMs both as adhesion molecules and as signal transduction molecules [22]. NCAM has been implicated as having a role in cell-cell adhesion, neurite outgrowth, synaptic plasticity, and learning and memory $[23,24]$. There is evidence that PHE-CoV is disseminated throughout the central nervous system by direct transfer of virus from neuron to neuron [25]. Thus, by binding to NCAM, the PHE-

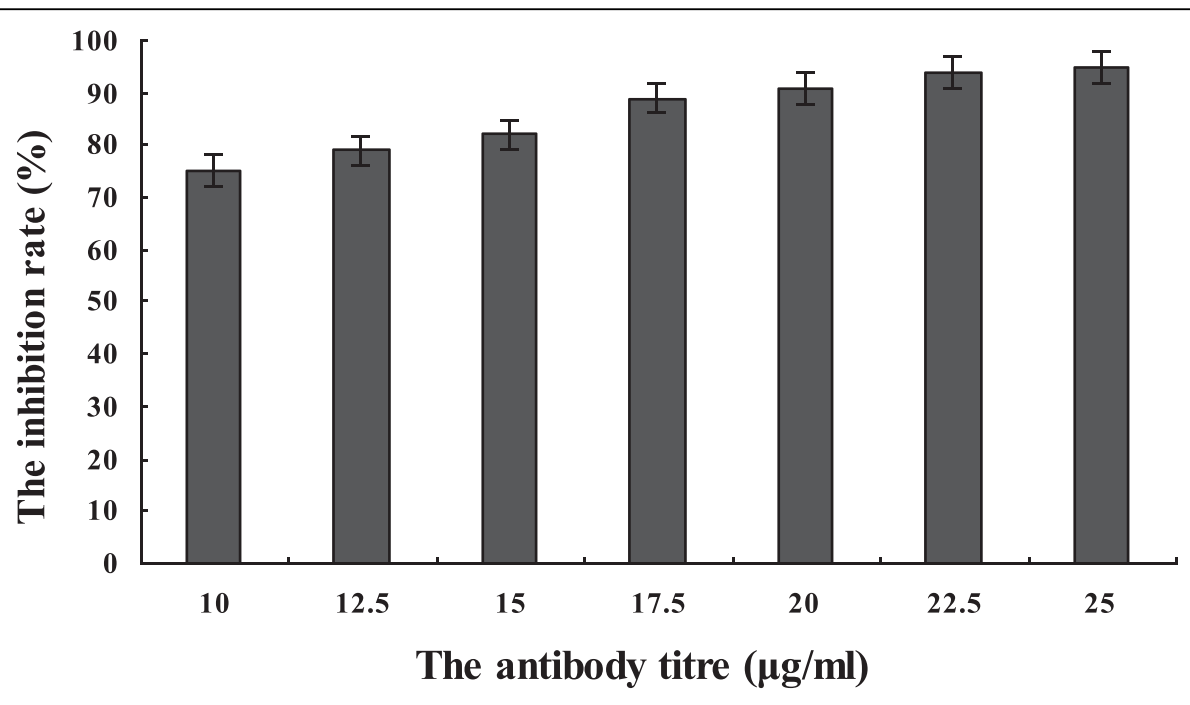

Figure 5 Anti-NCAM antibody inhibition of PHE-CoV binding to N2a cells. PHE-CoV binding assay using various concentrations of antiNCAM antibody. The $10 \mu \mathrm{g} / \mathrm{ml}$ anti-NCAM antibody inhibited PHE-CoV binding to N2a cells by $75 \%$. With the increased anti-NCAM antibody concentration in the blocking, the inhibition rate increased accordingly. The $25 \mu \mathrm{g} / \mathrm{ml}$ anti-NCAM antibody inhibited PHE-CoV binding to N2a cells by $95.7 \%$. However, the proliferation of virus could not be suppressed completely. 
Table 3 Oligonucleotides for siRNA construction

\begin{tabular}{ccl}
\hline siRNA & strand & Sequence \\
\hline SiNCAM799 & Antisense & 5'-AAGGTCTTGGAAAGCCCAAACCTGTCTC-3' \\
& Sense & 5'-AATTTGGCTTGCAAAGACCCCTGTCTC-3' \\
SiNCAM81 & Antisense & 5'-AAGTCTATGTGGTAGCTGAAACCTGTCTC-3' \\
& Sense & 5'-AATTCAGCTACCACATAGACCCTGTCTC-3' \\
SiNCAM90 & Antisense & 5'-AACTCTGTCGAACCTCACAAACCTGTCTC-3' \\
& Sense & 5'-AATTGTGAGGTTCGACAGAGCCTGTCTC-3' \\
siCtrl & Antisense & 5'-AATTGGGCTTGCAAAGACCTTCCTGTCTC-3' \\
& Sense & 5'-AATTCCAGAAACGTTCGGGTTCCTGTCTC-3' \\
\hline
\end{tabular}

$\mathrm{CoV}$ might increase the probability of gaining access form peripheral nervous system to the central nervous system.

Affected piglets show the clinical symptoms such as generalized muscle trembling, abnormal walking, lack of co-ordination, ears held back, convulsions and lying on the side and paddling legs. If PHE-CoV bind to NCAM, certain aspects of the clinical symptoms may be readily explained. NCAM is expressed in the surface of developing muscle with a spatiotemporal pattern that is consistent with a role in neuromuscular junction (NMJ) formation [26]. Only NCAM of the CAMs appears on the surface of muscle cells in parallel with the ability of the muscle cell surface to accept synapses [27]. Levels of NCAM in muscle are regulated in parallel with the susceptibility of muscle to innervation. NCAM-induced sprouting is thought to be induced via homophilic binding between NCAMs in the neural and the muscle surfaces, that in turn induces growth promoting mechanisms in the nerve process [26].

The close genetic and antigenic relatedness among the group 2 coronaviruses human coronavirus OC43 (HcoV-OC43), bovine coronavirus (BCV), and porcine hemagglutinating encephalomyelitis virus (PHE-CoV) suggests that these three viruses with different host specificities diverged fairly recently [1]. HcoV-OC43, BCV and PHE-CoV recognize sialic acid-containing receptors similar to those of influenza $C$ viruses [28-32]. Polysialic acid (PSA) is a developmentally regulated carbohydrate composed of a linear homopolymer of a-2,8-linked sialic acid residues [33]. NCAM undergoes post-translational modification during development, leading to the abundant addition of PSA chains on its extracellular domain [34]. PSA on NCAM is developmentally regulated thus playing a prominent role in different forms of neural plasticity spanning from embryonic to adult nervous system, including axonal growth, outgrowth and fasciculation, cell migration, synaptic plasticity, activity-induced plasticity, neuronal-glial plasticity, embryonic and adult neurogenesis [35].

The entry of coronaviruses is a multi-step process that involve: docking on the plasma membrane, binding to a receptor or co-receptors and delivery of the viral genome into the host cell. Docking of viruses on the plasma membrane of a susceptible cell is the first step during virus entry. Docking involves non-specific interactions between the viral envelope protein and carbohydrate moieties like heparan sulfate or sialic acid on the surface of cells. These initial docking interactions may lead to

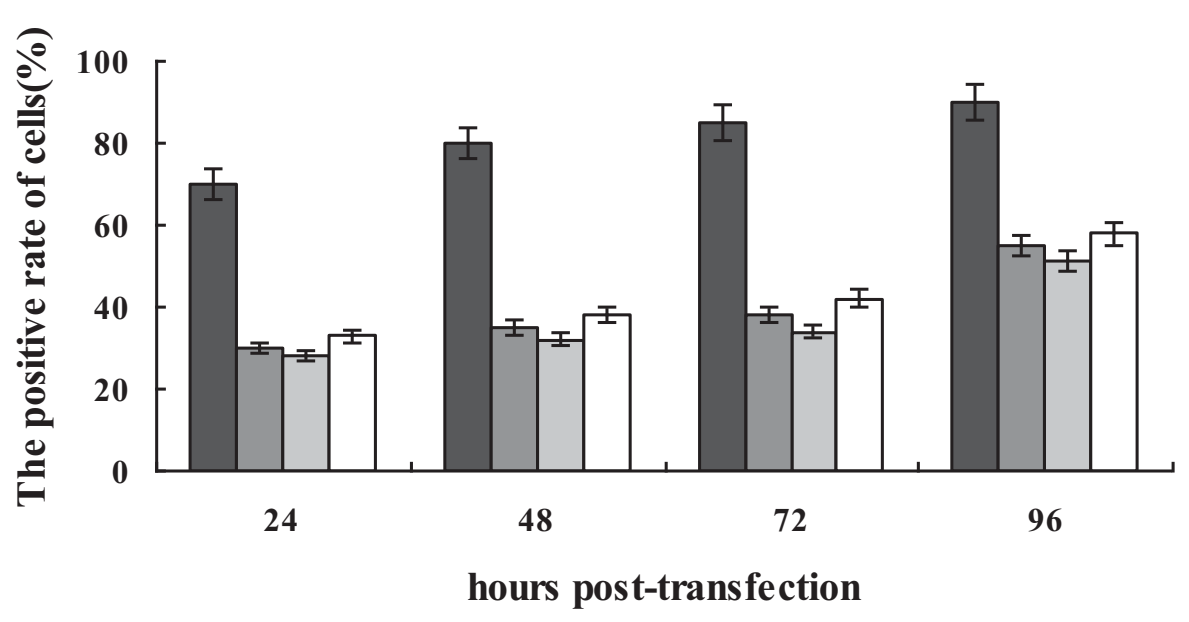

$\square$ Mock $\square \operatorname{siNCAM79} \square \operatorname{siNCAM81} \square \operatorname{siNCAM90}$

Figure 6 Double-stranded siRNA could effectively inhibit NCAM expression in N2a cells. N2a cells were transfected with siRNA targeted against NCAM. The cells were harvested after siRNA transfection and analyzed by FACS with rabbit anti-NCAM antibody and FITC-Conjugated goat anti-rabbit lgG $(\mathrm{H}+\mathrm{L})$. Mock-transfected siRNA N2a cells served as a control. There appeared to be a slight decrease of the positive rate of N2a KD cells compared to that of controls within 72 hours. 


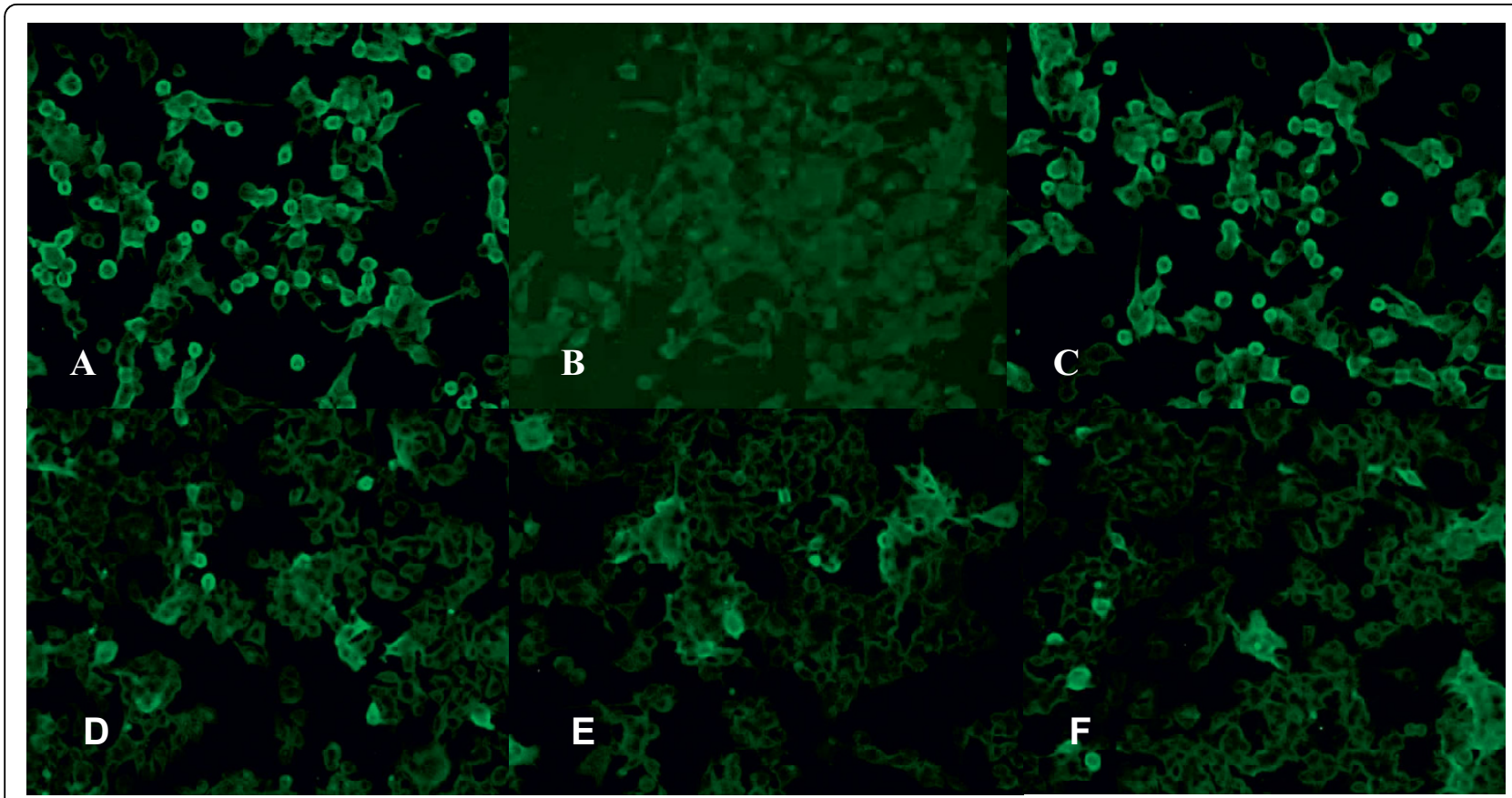

Figure 7 The NCAM siRNAs inhibit PHE-CoV infection by indirect immunofluorescence. After a $48 \mathrm{~h}$ viral infection, the N2a cells were fixed with $80 \%$ acetone for $10 \mathrm{~min}$ at $-20^{\circ} \mathrm{C}$, rehydrated in PBS, labeled with rabbit PHE-CoV antiserum, and washed three times with PBS. FITCconjugated goat anti-rabbit lgG $(\mathrm{H}+\mathrm{L})$ (1:50 dilution) was added to the N2a cell mixtures for $30 \mathrm{~min}$ at room temperature, and the cells were washed and observed with an Olympus FV1000 laser scanning confocal microscope. Microscopic magnification, 400x. (A) Mock transfection (stained with PHE-CoV-positive serum); (B) Mock transfection (stained with PHE-CoV-negative serum); (C) siCtrl transfection; (D) siNCAM79 transfection; (E) siNCAM81 transfection; (F) siNCAM90 transfection.

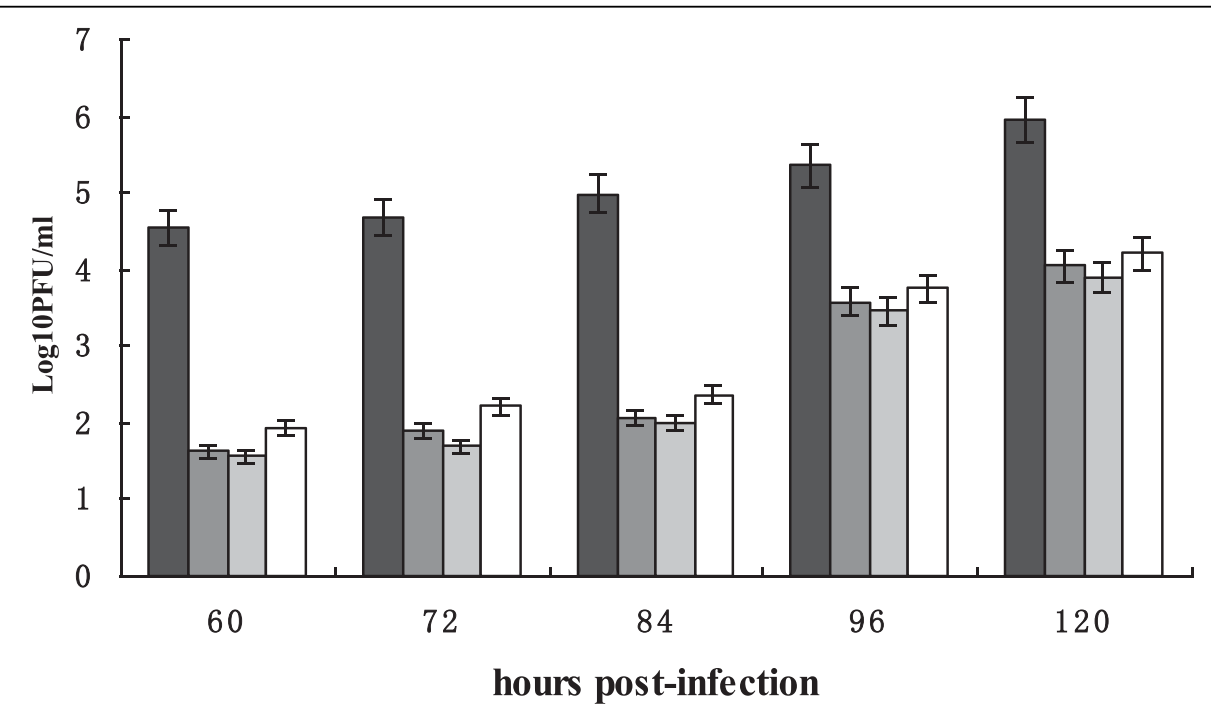

\section{$\square$ Mock+PHE-CoV $\square$ siNCAM79+PHE-CoV \\ $\square$ siNCAM81+PHE-CoV $\square$ siNCAM90+PHE-CoV}

Figure 8 The NCAM siRNAs could inhibit PHE-CoV infection in a period of time. Culture supernantants were collected 120 hours after the PHE-CoV challenge. The supernatants harvested at indicated timings were subjected to plaque assay. There was significant difference ( $p<0.05)$ in virus titres. Knock-down of NCAM caused a marked reduction of PHE-CoV infection within 84 hours. 
concentration of virus at the plasma membrane of a susceptible cell that in turn may enhance the infectivity of the virus by facilitating the interactions of the envelope protein with a cellular receptor that promotes virus entry. Reovirus strains that have sialic acid-binding activity attach to cells with 5 -fold more avidity than strains that do not bind sialic acid, and their infectivity is enhanced 50-100 fold [36]. After docking at the surface of a susceptible cell, the virus binds a receptor molecule(s) that in turn triggers conformational changes that result in virus entry. We speculate that the entry of PHE-CoV is a multi-step process. The Hemagglutininesterase (HE) protein of PHE-CoV binds to polysialic acid (PSA) moieties, while the spike (S) protein of PHE$\mathrm{CoV}$ binds to NCAM at the plasma.

Additionally, porcine hemagglutinating encephalomyelitis is an infectious disease affecting mainly pigs under 3 weeks old [37]. During the embryonic development of the brain, NCAM undergoes posttranslational modifications leading to the addition of a-2,8-polysialic acid (PSA) chains on its extracellular domain [38]. This embryonic highly PSA-NCAM is expressed abundantly throughout the brain until early postnatal period and is involved in neurite extension and synaptogenesis [38]. In the adult brain, however, PSA-NCAM expression is considerably reduced, although it has been shown to be expressed in certain areas (e.g. the olfactory bulb and hippocampus) [34].

Finally, identification of the NCAM that interacts with PHE-CoV spike protein will facilitate the description of the binding domain of the spike protein, which will presumably be the most effective target epitope for a spike protein-based subunit vaccine. In addition, it is likely that a cell line approved for vaccine production, and one that is made permissive for viral replication through expression of NCAM, will be the most efficient largescale producer of whole-killed or attenuated virus for use as a vaccine. There are a number of chronic neurologic diseases, such as myasthenia gravis, subacute sclerosing panencephalitis, and Alzheimer's disease, for which some evidence of viral etiology exists [39]. One explanation for these diseases is that after a virus binds to a cellular constituent acting as a receptor, the receptor might be altered. Identification of the specific neuronal constituents to which neurotropic viruses bind will allow for an analysis of the potential effects of these interactions on functional or antigenic alterations of receptors [40].

\section{Acknowledgements}

We thank American Journal Experts for excellent grammar revisions of this paper. This work was supported by the National Natural Science Foundation of China (No. 30671551 and No. 31072134).

\section{Author details}

${ }^{1}$ College of Animal Science and Veterinary Medicine, Jilin University, Changchun 130062, PR China. ${ }^{2}$ Key Laboratory of Zoonosis, Ministry of Education, Institute of Zoonosis, Jilin University, Changchun 130062, PR China. ${ }^{3}$ Laboratory Animal Center, Jilin University, Changchun 130062, PR China.

\section{Authors' contributions}

WG and WH carried out most of the experiments and wrote the manuscript. $\mathrm{HL}$ participated in the protein production. KZ carried out the coimmunoprecipitation assay. WR and CD participated in the sequence alignment. YL participated in the design of the NCAM siRNAs. KC participated in the design of the study. FG and DS conceived of the study and participated in its design and coordination. All authors read and approved the final manuscript.

\section{Competing interests}

The authors declare that they have no competing interests.

Received: 28 June 2010 Accepted: 24 September 2010 Published: 24 September 2010

\section{References}

1. Vijgen L, Keyaerts E, Lemey P, Maes P, Van Reeth K, Nauwynck H, Pensaert M, Van Ranst M: Evolutionary history of the closely related group 2 coronaviruses: porcine hemagglutinating encephalomyelitis virus, bovine coronavirus, and human coronavirus OC43. J Virol 2006, 80:7270-7274.

2. lacono KT, Kazi L, Weiss SR: Both spike and background genes contribute to murine coronavirus neurovirulence. Journal of Virology 2006, 80:6834-6843.

3. Li WH, Moore MJ, Vasilieva N, Sui JH, Wong SK, Berne MA, Somasundaran M, Sullivan JL, Luzuriaga K, Greenough TC, et al: Angiotensin-converting enzyme 2 is a functional receptor for the SARS coronavirus. Nature 2003, 426:450-454.

4. Miura TA, Travanty EA, Oko L, Bielefeldt-Ohmann H, Weiss SR, Beauchemin N, Holmes KV: The spike glycoprotein of murine coronavirus MHV-JHM mediates receptor-independent infection and spread in the central nervous systems of Ceacam1a(-/-) mice. Journal of Virology 2008, 82:755-763.

5. Phillips JJ, Chu MM, Lavi E, Weiss SR: Pathogenesis of chimeric MHV4/ MHV-A59 recombinant viruses: the murine coronavirus spike protein is a major determinant of neurovirulence. Journal of Virology 1999, 73:7752-7760.

6. Jeffers SA, Tusell SM, Gillim-Ross L, Hemmila EM, Achenbach JE, Babcock GJ, Thomas WD, Thackray LB, Young MD, Mason RJ, et al: CD209L (L-SIGN) is a receptor for severe acute respiratory syndrome coronavirus. Proceedings of the National Academy of Sciences of the United States of America 2004, 101:15748-15753.

7. Delmas B, Gelfi J, L'Haridon R, Vogel LK, Sjostrom H, Noren O, Laude H: Aminopeptidase $\mathrm{N}$ is a major receptor for the entero-pathogenic coronavirus TGEV. Nature 1992, 357:417-420.

8. Tresnan DB, Levis $\mathrm{R}$, Holmes $\mathrm{KV}$ : Feline aminopeptidase $\mathrm{N}$ serves as a receptor for feline, canine, porcine, and human coronaviruses in serogroup I. J Virol 1996, 70:8669-8674.

9. Wentworth $\mathrm{DE}$, Holmes $\mathrm{KV}$ : Molecular determinants of species specificity in the coronavirus receptor aminopeptidase $\mathrm{N}$ (CD13): influence of $\mathrm{N}$ linked glycosylation. J Virol 2001, 75:9741-9752.

10. Yeager CL, Ashmun RA, Williams RK, Cardellichio CB, Shapiro LH, Look AT, Holmes KV: Human aminopeptidase $\mathrm{N}$ is a receptor for human coronavirus 229E. Nature 1992, 357:420-422.

11. Andries K, Pensaert MB: Immunofluorescence studies on the pathogenesis of hemagglutinating encephalomyelitis virus infection in pigs after oronasal inoculation. Am J Vet Res 1980, 41:1372-1378.

12. Yagami K, Hirai K, Hirano N: Pathogenesis of haemagglutinating encephalomyelitis virus (HEV) in mice experimentally infected by different routes. J Comp Pathol 1986, 96:645-657.

13. Mengeling WL, Boothe AD, Ritchie AE: Characteristics of a coronavirus (strain 67N) of pigs. Am J Vet Res 1972, 33:297-308. 
14. Hirano N, Ono K, Takasawa H, Murakami T, Haga S: Replication and plaque formation of swine hemagglutinating encephalomyelitis virus $(67 \mathrm{~N})$ in swine cell line, SK-K culture. J Virol Methods 1990, 27:91-100.

15. Yao L, Yin J, Zhang X, Liu Q, Li J, Chen L, Zhao Y, Gong P, Liu C: Cryptosporidium parvum: identification of a new surface adhesion protein on sporozoite and oocyst by screening of a phage-display cDNA library. Exp Parasitol 2007, 115:333-338.

16. Prabhat P, Gan Z, Chao J, Ram S, Vaccaro C, Gibbons S, Ober RJ, Ward ES: Elucidation of intracellular recycling pathways leading to exocytosis of the Fc receptor, FcRn, by using multifocal plane microscopy. Proc Natl Acad Sci USA 2007, 104:5889-5894.

17. Gonzalez G, Pfannes L, Brazas R, Striker R: Selection of an optimal RNA transfection reagent and comparison to electroporation for the delivery of viral RNA. J Virol Methods 2007, 145:14-21.

18. Gupte J, Cutler G, Chen JL, Tian H: Elucidation of signaling properties of vasopressin receptor-related receptor 1 by using the chimeric receptor approach. Proc Natl Acad Sci USA 2004, 101:1508-1513.

19. Rondou P, Haegeman G, Vanhoenacker P, Van Craenenbroeck K: BTB Protein KLHL12 targets the dopamine D4 receptor for ubiquitination by a Cul3-based E3 ligase. J Biol Chem 2008, 283:11083-11096.

20. Auer S, Lappalainen RS, Skottman H, Suuronen R, Narkilahti S, VikholmLundin I: An antibody surface for selective neuronal cell attachment. J Neurosci Methods 2010, 186:72-76.

21. Johnson JP: Cell adhesion molecules of the immunoglobulin supergene family and their role in malignant transformation and progression to metastatic disease. Cancer Metastasis Rev 1991, 10:11-22.

22. Zhang Y, Yeh J, Richardson PM, Bo X: Cell adhesion molecules of the immunoglobulin superfamily in axonal regeneration and neural repair. Restor Neurol Neurosci 2008, 26:81-96.

23. Walsh FS, Doherty P: Neural cell adhesion molecules of the immunoglobulin superfamily: role in axon growth and guidance. Annu Rev Cell Dev Biol 1997, 13:425-456.

24. Dalva MB, McClelland AC, Kayser MS: Cell adhesion molecules: signalling functions at the synapse. Nature Reviews Neuroscience 2007, 8:206-220.

25. Hirano N, Tohyama K, Taira H: Spread of swine hemagglutinating encephalomyelitis virus from peripheral nerves to the CNS. Adv Exp Med Biol 1998, 440:601-607.

26. Lain E, Carnejac S, Escher P, Wilson MC, Lomo T, Gajendran N, Brenner HR: A Novel Role for Embigin to Promote Sprouting of Motor Nerve Terminals at the Neuromuscular Junction. Journal of Biological Chemistry 2009, 284:8921-8930.

27. Sanes JR, Schachner $M$, Covault J: Expression of several adhesive macromolecules (N-CAM, L1, J1, NILE, uvomorulin, laminin, fibronectin, and a heparan sulfate proteoglycan) in embryonic, adult, and denervated adult skeletal muscle. J Cell Biol 1986, 102:420-431.

28. Vlasak R, Luytjes W, Spaan W, Palese P: Human and bovine coronaviruses recognize sialic acid-containing receptors similar to those of influenza $C$ viruses. Proc Natl Acad Sci USA 1988, 85:4526-4529.

29. Schultze B, Herrler G: Bovine coronavirus uses N-acetyl-9-O -acetylneuraminic acid as a receptor determinant to initiate the infection of cultured cells. J Gen Virol 1992, 73(Pt 4):901-906.

30. Rogers GN, Herrler G, Paulson JC, Klenk HD: Influenza C virus uses 9-Oacetyl-N-acetylneuraminic acid as a high affinity receptor determinant for attachment to cells. J Biol Chem 1986, 261:5947-5951.

31. Schultze B, Gross HJ, Brossmer R, Klenk HD, Herrler G: Hemagglutinating encephalomyelitis virus attaches to $\mathrm{N}$-acetyl-9-O-acetylneuraminic acidcontaining receptors on erythrocytes: comparison with bovine coronavirus and influenza C virus. Virus Res 1990, 16:185-194.

32. Zeng $Q$, Langereis MA, van Vliet $A L$, Huizinga $E G$, de Groot RJ: Structure of coronavirus hemagglutinin-esterase offers insight into corona and influenza virus evolution. Proc Natl Acad Sci USA 2008, 105:9065-9069.

33. Murphy JA, Hartwick AT, Rutishauser U, Clarke DB: Endogenous polysialylated neural cell adhesion molecule enhances the survival of retinal ganglion cells. Invest Ophthalmol Vis Sci 2009, 50:861-869.

34. Arellano Jl, DeFelipe J, Munoz A: PSA-NCAM immunoreactivity in chandelier cell axon terminals of the human temporal cortex. Cereb Cortex 2002, 12:617-624.

35. Bonfanti L: PSA-NCAM in mammalian structural plasticity and neurogenesis. Prog Neurobiol 2006, 80:129-164.
36. Barton ES, Connolly JL, Forrest JC, Chappell JD, Dermody TS: Utilization of sialic acid as a coreceptor enhances reovirus attachment by multistep adhesion strengthening. J Biol Chem 2001, 276:2200-2211.

37. Quiroga MA, Cappuccio J, Pineyro P, Basso W, More G, Kienast M, Schonfeld S, Cancer JL, Arauz S, Pintos ME, et al: Hemagglutinating encephalomyelitis coronavirus infection in pigs, Argentina. Emerg Infect Dis 2008, 14:484-486.

38. Barbeau D, Liang JJ, Robitalille Y, Quirion R, Srivastava LK: Decreased expression of the embryonic form of the neural cell adhesion molecule in schizophrenic brains. Proc Natl Acad Sci USA 1995, 92:2785-2789.

39. Valenciano Clavel L: [Slow virus infections of the nervous system]. Rev Sanid Hig Publica (Madr) 1973, 47:807-818.

40. Lentz TL, Burrage TG, Smith AL, Tignor GH: The acetylcholine receptor as a cellular receptor for rabies virus. Yale J Biol Med 1983, 56:315-322.

doi:10.1186/1743-422X-7-254

Cite this article as: Gao et al:: Identification of NCAM that interacts with the PHE-CoV spike protein. Virology Journal 2010 7:254.

\section{Submit your next manuscript to BioMed Central and take full advantage of:}

- Convenient online submission

- Thorough peer review

- No space constraints or color figure charges

- Immediate publication on acceptance

- Inclusion in PubMed, CAS, Scopus and Google Scholar

- Research which is freely available for redistribution

Submit your manuscript at www.biomedcentral.com/submit
Ciomed Central 